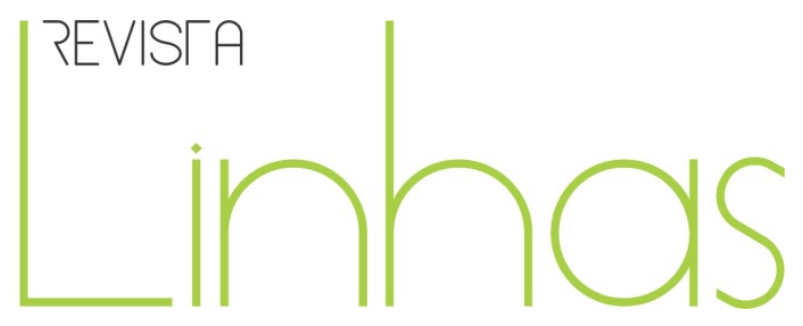

\title{
Genealogia e imoralidade: o currículo entre experimentações nômades e estratificações sedentárias
}

\begin{abstract}
Resumo
Este estudo apresenta os objetivos de uma pesquisa sobre especificidades curriculares em espaços escolarizados e não escolarizados. Ao problematizar o currículo, está comprometido com a questão da valoração, ou seja: por que certos tipos de conhecimento, sujeito e subjetividade são desejáveis em detrimento de outros? Trata-se, através do método genealógico proposto por autores como Friedrich Nietzsche e Michel Foucault, de perguntar sobre as forças que compõem o currículo, sobre os critérios morais para decidir o que é bom e o que é mau, o que é certo e o que é errado no currículo. Pergunta-se: para quem o currículo é um valor, em que circunstâncias foi criado, que forças estiveram em luta na sua criação e imposição? Tomando-se o valor e o conhecimento como invenções, e não como dados naturais transcendentes, afirma-se o caráter histórico, acidental e contingente dos valores curriculares problematizados, abrindo-se a possibilidade de sua recriação - não se trata de uma invalidação, tampouco de uma renúncia, mas de um apontamento: o valor colocado em seu devido lugar, problematizado. A pesquisa, ainda em fase inicial, através de entrevistas, registros, análise de documento e observações, busca desenvolver diversos olhares sobre o currículo escolar enquanto território coletivo e político que interage com forças diferenciadas, dispositivos disciplinares e possibilidades de experimentação.
\end{abstract}

Palavras-chave: Currículo; Espaços escolarizados e não escolarizados; Genealogia.

\footnotetext{
Para citar este artigo:

COSTA, Cristiano Bedin da; MUNHOZ, Angelica Vier. Genealogia e imoralidade: o currículo entre experimentações nômades e estratificações sedentárias. Revista Linhas. Florianópolis, v. 15, n. 29, p. $423-$ 437, jul./dez. 2014.
}

DOI: $10.5965 / 1984723815292014423$

http://dx.doi.org/10.5965/1984723815292014423

Cristiano Bedin da Costa

Doutor em Educação pela

Universidade Federal do Rio Grande do Sul - UFRGS - Brasil cristianobedindacosta@hotmail.com

\section{Angelica Vier Munhoz}

Doutora em Educação pela

Universidade Federal do Rio Grande do Sul - UFRGS - Brasil angelicavmunhoz@gmail.com 


\title{
Genalogy and immorality: the curriculum between nomadic experiments and sedentary stratifications
}

\begin{abstract}
This study presents the objectives of a research into curriculum specificities in both schooled and unschooled spaces. By problematizing the curriculum, the study is focused on the valorization issue, i.e. why are certain kinds of knowledge, subject and subjectivity desirable, rather than others? Through the genealogic method proposed by authors such as Friedrich Nietzsche and Michel Foucault, we ask about the forces that compose the curriculum, about moral criteria adopted to decide what is good and what is bad, what is right and what is wrong in the curriculum. We ask: For whom is the curriculum a value? In which circumstances was it created? Which forces struggled along its creation and imposition? By regarding both value and knowledge as inventions, rather than transcendent natural data, the historical, accidental and contingent character of the problematized curricular values is insured, thus allowing the possibility of its recreation - it is neither invalidation, nor renouncement, but rather an indication: value is put in its due place and is problematized. The research, which is still at its early stage, by means of interviews, records, documental analysis and observations, attempts to develop several ways of regarding the school curriculum as a collective and political territory that interacts with different forces, disciplinary devices and possibilities of experimentation.
\end{abstract}

Keywords: Curriculum; Schooled and unschooled spaces; Genealogy. 
Este é um texto-mapa. Rápido e incompleto porque necessariamente móvel, quer-se desmontável, passível de constantes modificações, anulável, reprogramável, reversível e adaptável a “montagens de qualquer natureza” (DELEUZE; GUATTARI, 1995, p. 22). Não faz mais que apontar direções, caminhos possíveis a uma pesquisa que se inicia ${ }^{1}$. Filosoficamente articulado ao pensamento da diferença proposto por Friedrich Nietzsche, contagia-se e se prolifera, em tal meio, por conceitos, movimentos e problematizações foucaultianas, barthesianas, deleuzo-guattarianas... Ora, como dizer de quem ou por quantos mais? Bem sabemo-nos bricoleurs, (DELEUZE; GUATTARI, 2010, p. 11) com nossas incontáveis ligações e conexões, e nesse nosso esforço "há portos, hotéis e camas" (CORTÁZAR, 2008, p. 11) para inomináveis outros, topologia fina, múltipla e palimpséstica: “o futuro, pois, pertence à filofonia” (SATIE, 1992, p. 43). Assim, não constitui aqui um programa fixo, não elabora e estrutura a totalidade dos movimentos seguintes, tornando-se, desde já e a cada nova investida, composição e performance, em detrimento ao modelo, à competência e à rigidez organizativa. Ao enunciar com quem anda, aceitando assim quem é (CORAZZA, 2010, p. 143-171), este texto sabe-se feito por nômades e para nômades (DELEUZE; GUATTARI, 1997, p. 11-110), ou seja, sob todas as coordenadas temporais e espaciais através das quais o movimento pode ser medido, controlado, calculado, postula a velocidade intensiva enquanto valor a ser preservado

\footnotetext{
${ }^{1}$ Trata-se de uma pesquisa intitulada "O currículo em espaços escolarizados e não escolarizados no Brasil e na Colômbia: diferentes relações com o aprender e o ensinar", vinculado ao Mestrado em Ensino do Centro Universitário UNIVATES/RS. A referida pesquisa tem por objetivo investigar as especificidades curriculares em espaços escolares e não escolares e suas relações e cruzamentos com os movimentos escolarizados e não escolarizados, a partir de aproximações com a genealogia. O campo empírico da pesquisa são dois espaços escolares (Escuela Pedagógica Experimental - Bogotá/Colômbia e Escola Municipal Porto Novo Lajeado/RS) e dois espaços não escolares (ONG Abaquar - Lajeado/RS e Fundação Iberê Camargo - Porto Alegre/RS). A pesquisa, ainda em fase inicial, através de entrevistas, registros, análise de documento e observações, busca desenvolver diversos olhares sobre o currículo escolar enquanto território coletivo e político que interage com forças diferenciadas, dispositivos disciplinares e possibilidades de experimentação.
} 
(CALVINO, 1990), defendendo assim a educação como prática inventiva, destacada o tanto possível dos exercícios exaustivos do comentário, do monólogo e da repetição.

\section{De seus lineamentos}

“Indivíduos ou grupos, somos todos feitos de linhas" (DELEUZE; PARNET, 1998, p. 142). Descontínuas. Sitiadas. Retas. Curvas. Modulares. Seguras. Transicionais. Quebradas. Móveis. Conectivas. Flutuantes. Residuais. Irregulares. Fragmentárias. Insignificantes. Vazias. Pequenas. Longas. Pesadas. Suaves. Molares. Mortais. Sós. Ao voltarmo-nos para um currículo, dessa maneira, não temos outro objeto prático: com quais linhas lidamos? Quais mapas faremos, ampliaremos, remanejaremos? Quais linhas abstratas traçaremos? Como? A partir de qual ponto e a que preço? Rachamos? Cairemos? Racharemos? Quais são as linhas por nós interrompidas? Decalcadas? Mortas? Criadas? Prolongadas? Retomadas? Lineamentos: eis no que incidimos. $\mathrm{O}$ curso. A aula. $\mathrm{O}$ livro. A teoria. $\mathrm{O}$ autor. O estágio. A diretriz. O turno. A turma. A disciplina. $\mathrm{O}$ um ou o outro. Um após o outro: segmentos, determinações, recortes, direções. Ou então, concomitantemente e em outro nível: saltos, desertos, constelações, fugas, risos. Movimentos livres. Rasurados. Entrelaçados. Traçados de tempo. Traçados de espaço. Traçados que se perdem. Desvios, pequenas modificações, colapsos, delineamentos de quedas ou impulsos, devires. Um e outro. Contágio. Proliferação. Onde "um limiar é ultrapassado, e não coincide, necessariamente, com um segmento das linhas mais visíveis" (DELEUZE; PARNET, 1998, p. 145). Uma outra política, um outro tempo, um outro espaço, uma outra história, uma outra individuação. Somos todos complicados, "temos tantas linhas emaranhadas quanto a mão" (idem, p.146): linhas duras e segmentarizadas, linhas moleculares e limiares de intensidade, linhas que daí, talvez, se deslocam a um destino desconhecido, não previsível, não preexistente: é quando a linha se torna fuga, e quando fugir é fazer fugir, esquivar, escapar, perder a estanqueidade e a clausura, redistribuir os possíveis em uma situação "perfeitamente improgramável, ligada à imprevisível criação de novos espaçostempos" (ZOURABICHVILI, 2004, p. 58). Traçar uma linha, ou simplesmente fazer um 
sistema vazar: na educação, assim como na vida, só se cria, "só se descobre mundos através de uma longa fuga quebrada" (DELEUZE; PARNET, 1998, p. 49), tendo as fronteiras como algo a ser transposto, rechaçado, ultrapassado: Geocurrículo (CORAZZA, 2010) sem juízo, ocupado em experimentar, conectar, fazer existir, dar a ver, a pensar, a sentir, a maquinar, a viver em meio ao impensado que o compõe em suas ressonâncias.

(...) existe outra força, que nasce não no ponto, mas fora dele. Essa força se precipita sobre o ponto preso no plano, arranca-o daí e empurra-o para uma direção qualquer. Assim, a tensão concêntrica do ponto vê-se destruída e o ponto desaparece, dele resultando um novo ser, dotado de uma vida autônoma e submetido a outras leis. (KANDINSKY, 1997, p. 45)

Tal como refere Deleuze (1992), é quando não se reconhece, quando se tem dificuldade em reconhecer, que se pensa verdadeiramente. Necessidade efetiva de uma violência, de uma estranheza ou verdadeira inimizade, para que o pensamento seja retirado de sua e-terna possibilidade. Pensar é descolar, e em tal plano, não contamos com o pensamento para fundar a necessidade relativa do que ele pensa. Antes, conta-se com a contingência de um encontro com aquilo que força, violenta o pensar (HEUSER, 2010), estabelecendo assim a necessidade absoluta de um ato de pensamento, de relançamento de possíveis. Nessa perspectiva, pensar já não é uma simples questão de teoria, mas sim de vida, de estilo de vida implicado, de maneira que o critério da teoria, por sua vez, não será o teórico, mas sim pragmático: que modos de existência isso implica? Que saídas, ou pelo contrário, que armadilhas, a vida aí encontra? "Tinha-se escolhido o Lugar, a Potência, o Coletivo" (DELEUZE; GUATTARI, 1995, p. 12), mas eis que o lugar já era ele próprio um topos-instrumento, espaço de con-tensão (COUTO, 2001, p. 130), e não domesticação, no qual a vida, a potência, a dinâmica, não se diluem, não perdem sua força de libertação, ainda que isso não implique uma queda no indiferenciado, na desestruturação catastrófica de todo o dispositivo formal. Ao contrário, a linha de fuga deve in-formar alguma outra forma que contenha a tensão, a vertigem, o limite: desfazer a organização pontual, a figuração, a representação, em nome de uma obra afectiva, de estruturações intensas, sensíveis, maquínicas. Tal como 
afirma Jaques Rancière (2000, p. 505), compreender um pensamento não é chegar a coincidir com seu centro, mas, ao contrário, deportá-lo, conduzi-lo a uma trajetória em que suas articulações se afrouxam e permitem um novo jogo, onde seja possível desfigurar o pensamento para refigurá-lo de outro modo, sair da restrição de seus limites para enuncia-lo em outra terra, necessariamente estrangeira - onde a educação, conservando a sutileza estética de lutar, ameaça o império da verdade e sua entropia mortífera (CORAZZA, 2010, p. 151).

\section{De sua graça}

Tal como nos mostrou Nietzsche (2001), o intelecto é, para a grande maioria das pessoas, “uma máquina pesada, escura e rangente, difícil de pôr em movimento”. Assim, acostumamo-nos a chamar de "levar a coisa a sério", quando trabalhamos e queremos pensar bem com essa máquina. Ao que parece, estamos fadados a perder o bom humor toda vez que pensamos bem: nessas horas, ficamos sérios, devemos ficar sérios, pois “onde há riso e alegria, o pensamento nada vale” (NIETZSCHE, 2001, p. 217). É apenas com graça, portanto, que se pode questionar a militância dos que defendem a gravidade e a estabilidade das certezas. E é com graça que se pode preferir, em detrimento ao que comumente se entende por boa consciência educacional, política, moral ou estética, a posição instável e digna de riso de uma prática impura, que faz de um habitáculo em deriva a sua doutrina, esforçando-se por se manter, o tanto quanto possível, distante de qualquer relação estratificada de poder, e alegrando-se por ser mais subversiva do que propriamente formadora ou até mesmo revolucionária. É assim, com graça, que o estudo do currículo, frente à carceragem dos sentidos, dos valores, da integralização da cultura, pode escolher como divisa um "sistema de provocações" (CORAZZA, 2010, p. 152) absolutamente imoral cujo lema seja: “eu decepciono". Ora, tal como nos adverte Nietzsche (2001, p. 216), todos os pregadores de moral têm uma incivilidade em comum: "todos eles procuram convencer os homens de que estão muito mal e precisam de um tratamento duro, radical, definitivo". Todos esses mestres, durante séculos inteiros muito zelosamente ouvidos, não nos deixam outra possibilidade - caso não desejemos fazer da 
educação e da vida algo apenas a suportar - que não "nos afastarmo-nos das coisas até que não mais vejamos muita coisa delas" ou então que as possamos "ver de soslaio e como que em recorte", para assim, afirmativamente, sermos "poetas-autores de nossas próprias práticas", (ídem, p. 202), principiando pelas coisas mínimas e cotidianas.

\section{De o que pensa e de o que quer}

Gostaria, pois que a fala e a escuta que aqui se trançarão fossem semelhantes às idas e vindas de uma criança que brinca em torno da mãe, dela se afasta e depois volta, para trazer-lhe uma pedrinha, um fiozinho de lã, desenhando assim ao redor de um centro calmo toda uma área de jogo, no interior da qual a pedrinha ou a lã importam finalmente menos do que o dom cheio de zelo que deles se faz. (BARTHES, 2007, p. 42)

Interessa-nos o currículo e suas especificidades em espaços escolarizados e não escolarizados. Desse modo, arquitetamos os nossos movimentos em meio a questões sabidamente centrais a qualquer teorização curricular pós-estruturalista (CORAZZA; TADEU, 2003, p. 37), quais sejam: a discussão sobre o conhecimento e a verdade, o sujeito e a subjetividade, os valores e o poder. Assim, a questão sobre o que é ou deve ser ensinado não se separa da problematização sobre o que, em determinado tempo e espaço, constitui-se como conhecimento válido, verdadeiro, ou, em outras palavras, o que "quer” (CORAZZA, 2001) determinada organização curricular. Ora, todo currículo carrega alguma noção de subjetivação e de sujeito, capaz de ser compreendida através da análise daquilo que ele pensa ser e no que busca tornar aqueles que são por ele envolvidos. Tal reflexão sobre as motivações, escolhas e juízos curriculares não se faz a não ser em meio à análise das relações de poder aí implicadas, ou seja, a genealogia dos valores morais (NIETZSCHE, 1998) que movimentam este ou aquele currículo: por que estes conhecimentos e não outros são considerados certos e verdadeiros? Por que determinado tipo de formação e não outra? Por que esse sujeito e não outro? Longe de qualquer crença em fundamentos primeiros e verdades transcendentes, interessa-nos perguntar pelas forças constituintes de todo processo valorativo: 
Em vez, pois, de perguntar 'o que é?', perguntar 'o que faz que seja o que é? Buscar, antes, o impulso, o desejo, o motivo que faz com que as coisas tenham o sentido que têm do que sua essência, sua origem ou o seu fundamento último. No lugar de uma ontologia, uma ciência das forças. (CORAZZA; TADEU, 2003, p. 49)

Entendendo que as verdades de um currículo não preexistem a ele, e que sua existência só faz sentido em uma determinada relação de poder (FOUCAULT, 2004, p. 1538) por ele encenada e encarnada, articulamo-nos ao pensamento do currículo enquanto imposição de sentidos, de valores, de modos de subjetivação particulares (SILVA, 1996, p. 193). Em uma visão tradicionalmente aceita, o currículo é uma organização da experiência de forma a transmitir, além do conhecimento, um conjunto bem definido de valores. Mais do que um empreendimento epistemológico, um esforço moral (CORAZZA; TADEU, 2003, p. 53). Frente a tal quadro, ao propor um estranhamento de tais formas de governamento, de regulação dos sujeitos e das coisas (FOUCAULT, 2004, p. 277-293) como programa com função educativa, não cabe, tal como nos ensina Deleuze (1992, p. 220), temer ou esperar, mas "buscar novas armas", capazes de desconectar o currículo dos movimentos escolarizantes que agem na delimitação de suas fronteiras.

Ao tomar o escolarizado e o não escolarizado como noções a serem estudadas, entendemos que o currículo deve ser pensado em razão das posturas e das relações que engendra, ou seja, pelo modo como, em seus movimentos, o espaço é ocupado (DELEUZE; PARNET, 1998, p. 31). Por essa via, a simples distinção entre escolar e não escolar não parece ser suficiente para garantir tal problematização, uma vez que carrega consigo a pressuposição de que o escolar, com as normas que o governam, não traz consigo as forças necessárias a possíveis transmutações - e, por via inversa, a crença de que quaisquer esforços práticos de questionamento aos modelos escolares instituídos garantiriam a obtenção de um espaço livre de regulações.

Em meio a experimentações nômades e formações sedentárias, interessa-nos pensar as passagens e as combinações, as alternâncias e sobreposições entre as operações de alisamento e estriagem (DELEUZE; GUATTARI, 1997, p. 52-53), ou seja, de que modo os movimentos criadores não cessam de ser rebatidos e remanejados por uma 
maquinaria normativa, ao mesmo tempo em que a organização dos saberes, das práticas, da vida, pode entrar em um movimento contínuo de desprendimento de valores, medidas e propriedades. No fundo, a persistência de uma questão apenas: como fazer deste lugar, outro. Trata-se de uma tática de desarticulação, e não abandono.

\section{De três posturas espaciais}

Uma questão de postura: habitar o espaço nomadicamente, e não de forma sedentária; postular a velocidade enquanto valor a ser preservado, sob todas as coordenadas temporais e espaciais através das quais o movimento é medido; defender o pensamento em seu sentido forte, ou seja, real potência de criação e instauração de uma nova terra, e não um exercício de representação, adequação e permanência.

Em seu "Tratado de nomadologia", Deleuze e Guattari (1997, p. 11-110) nos lembram que, apesar de possuir um território, seguir trajetos costumeiros, ir de um ponto a outro, a vida nômade é aquela na qual tais demarcações não são princípios, mas simples consequências (criar e habitar o deserto tanto quanto por ele se é criado). Ao contrário do sedentário, o nômade é aquele para o qual o ponto - componente direcional, eixo frágil ao redor do qual delimitamos um meio, uma pose, um território existencial (DELEUZE; GUATTARI, 1997) - está subordinado ao trajeto, e mesmo os elementos de seu hábitat são concebidos em função do trajeto que não cessa de mobilizá-los. Para o nômade, a relação com a terra é constituída pela própria desterritorialização, e é mesmo nela que ele haverá de se reterritorializar. De certo modo, é o próprio itinerário, e não o território fixo, que vai constituir o hábitat enquanto exercício de impermanência. Corpos tendas, corpos yurts. Necessariamente, para a existência nômade, “o ponto de água só existe para ser abandonado" (idem, p. 50), mas isso não implica um movimento extensivo: antes, um fazer deste lugar, outro, ou seja: abrir-se, criar uma nova sensibilidade, novas antenas, conectar-se a pulsões de fuga que atravessam todos os indivíduos, mesmo os mais sedentários (FEIL, 2009), e desse modo operar por desarticulação, e não abandono. Tal como referem Deleuze e Guattari (1997, p. 52), “é 
falso definir o nômade pelo movimento", uma vez que a questão aí é sempre a de uma velocidade intensiva sob os movimentos extensivos ${ }^{2}$. Trata-se da constituição de dois tipos distintos de espaço: sedentário estriado, nômade liso:

[...] por mais que o trajeto nômade siga pistas ou caminhos costumeiros, não tem a função do caminho sedentário, que consiste em distribuir aos homens um espaço fechado, atribuindo a cada um a sua parte, e regulando a comunicação entre as partes. $O$ trajeto nômade faz o contrário, distribui os homens [...] num espaço aberto, indefinido, não comunicante [...] $\mathrm{O}$ espaço sedentário é estriado, por muros, cercados e caminhos entre os cercados, enquanto o espaço nômade é liso, marcado apenas por "traços" que se apagam e se deslocam com o trajeto [...] O nômade se distribui num espaço liso, ele ocupa, habita, mantém esse espaço, e aí reside seu princípio territorial. (DELEUZE; GUATTARI, 1997, p. 51-52)

A distinção entre o liso e o estriado, tal como é proposta por Pierre Boulez (2005) no campo musical (o liso enquanto nomos, espaço-tempo direcional, irregular e não determinado, que se ocupa sem contar e pode efetuar-se onde quiser; o estriado relativo a um logos, um espaço-tempo dimensional, definido por um padrão, que se conta a fim de ocupar), e retomada por Deleuze e Guattari em Mil Platôs (1997, p. 179-214), aponta para dois conceitos que devem ser diferenciados, antes de qualquer coisa, pela relação inversa do ponto e da linha, a saber: a linha de movimento traçada entre dois pontos, no caso do estriado (espaço dimensional, de intervalos fechados), e o ponto subordinado a duas linhas, ao trajeto, no caso do liso (espaço direcional, intervalos abertos, desenvolvimento e variações contínuas da forma). No espaço estriado, portanto, fecha-se uma superfície, que haverá de ser 'repartida' segundo intervalos determinados, conforme cortes assinalados que acabarão por ordenar as formas que aí se sucedem; no liso, por

\footnotetext{
2 “[...] o nômade é antes aquele que não se move. Enquanto o migrante abandona um meio tornado amorfo ou ingrato, o nômade é aquele que não parte, não quer partir, que se agarra a esse espaço liso onde a floresta recua, onde a estepe e o deserto crescem, e inventa o nomadismo como resposta a esse desafio [...] O movimento é extensivo, a velocidade, intensiva. O movimento designa o caráter relativo de um corpo considerado como 'uno', e que vai de um ponto a outro; a velocidade, ao contrário, constitui o caráter absoluto de um corpo cujas partes irredutíveis [...] ocupam e preenchem um espaço liso, à maneira de um turbilhão, podendo surgir num ponto qualquer [...] Em suma, diremos, por convenção, que só o nômade tem um movimento absoluto, isto é, uma velocidade". (DELEUZE e GUATTARI, 1997, p. 52-53)
} 
sua vez, 'distribui-se' num espaço aberto, conforme frequências e ao longo dos percursos. O espaço nômade, desse modo, pode ser localizado, mas não delimitado.

Tal oposição, no entanto, não é situada de maneira simples. Se é verdade que o espaço liso se configura por uma arquitetura nômade e intensiva, sob a medida do tempo e da dimensão física do espaço, subordinando assim toda formação pontual à força e às determinações de seu trajeto, também é fato que ele "não para de ser traduzido, transvertido num espaço estriado", sendo o último "constantemente revertido, devolvido a um espaço liso" (DELEUZE; GUATTARI, 1997, p. 180). De certo modo, ambos se fazem possíveis graças às misturas entre si, e toda a variação, todo o desenvolvimento contínuo das formas diz respeito à determinada maneira de se ocupar o espaço: habitá-lo de modo incerto, de maneira puramente direcional, irregular e não determinada - fazer do plano um Saara, perfurar o espaço com as escalas de um Saara, tal como Francis Bacon (cf. SYLVESTER, 2007, p. 56) demarca os desejos e os movimentos de uma arte cartográfica (habitar um deserto, esboçar seus limites, articular-se ao seu corpo, toda uma nova geografia); ou então, ao contrário, defini-lo por um corte dimensional, estratificando-o em padrões capazes de subordinar a totalidade dos movimentos que nele são produzidos.

É preciso ter em mente, portanto, o espaço liso, a linha desértica que percorre subterraneamente, virtualmente, a totalidade da matéria vivida. Frente a tal realidade, o educar não se deixa pensar isolado de um "de-formar”, do mapeamento de proporções desérticas em meio aos modelos de ensino, do pôr-algum-Saara-no-cérebro, liberando as práticas pedagógicas do claustrofóbico sentido das possibilidades dadas e das ideias feitas (CORAZZA; TADEU; ZORDAN; 2004, p. 167). Nomadismo, axioma primeiro: habitar o deserto, configurar-se em experimentação, velocidade e errância, evitando ao máximo os processos sedentários de estratificação. 


\section{De uma defesa}

Os movimentos, passagens, as trocas de saberes em currículos não escolarizados, sejam eles escolares ou não, podem configurar-se através de aprenderes desvinculados de resultados, de significações reduzidas por ações pedagógicas. Em tal perspectiva, a proposta de um currículo não escolarizado é também um esforço de oposição e de luta contra a coerção de discursos teóricos, unitários, formais e discursivos, através do reconhecimento de saberes nômades, de fronteira, ativados contra a hierarquização científica do conhecimento e de seus efeitos intrínsecos de poder (FOUCAULT, 2004, p. 172). Tecer em conjunto esses espaços - escolares e não escolares -, assim como os movimentos escolarizados e não escolarizados, tem por finalidade buscarmos entender de que modo o currículo pode se compor e se cruzar com novas práticas, outras experimentações e relações de saber.

\section{De o que assume}

Valores: critérios para decidir o que, na conduta humana, é bom e o que é mau, o que é desejável e o que é indesejável. Reunidos, esses critérios formam a "moral". A moral é universal: seus critérios valem para todos. É transcendental: os valores são deduzidos de algum princípio fundamental, inquestionável; são remetidos a algum ente supremo. A moral é eterna: não tem começo nem fim. O moralismo busca a origem primeira e o fim último dos valores. (CORAZZA; TADEU, 2003, p. 44)

Pensar genealogicamente as relações entre o currículo e a moral significa, antes de qualquer outra coisa, abrir mão de qualquer hipótese transcendental que viria a justificar e tornar absoluto o caráter de determinados valores, sejam eles quais forem. No lugar do azul onde placidamente repousariam a verdade e as essências, o cinza-terra da “longa, quase indecifrável escrita hieroglífica” de nosso passado moral (NIETZSCHE, 1998, p. 13). Por essa perspectiva, mais importante que os valores em si é o questionamento 
dos modos através dos quais são enunciados, as posições, os tempos e os espaços que engendram através das relações de poder que eles encarnam e que legitimam a sua instauração e manutenção em detrimento a outros. O cinza genealógico nietzschiano é também o cinza pictural de Paul Klee (1979), o ponto neutro entre as dimensões, que ao ser composto pela indiferenciação dos termos postos em relação, burla toda imposição de sentido instaurada pela configuração de um paradigma (BARTHES, 2003, p. 16-18). Ao escolher partir dos fatos indistintamente, a pesquisa genealógica situa-se à esquerda dos critérios normativos, e deles não se aproxima a não ser de maneira crítica. É desta maneira que se torna possível a ativação de saberes não legitimados, assim como a defesa dos mesmos contra qualquer “instância teórica unitária que pretenderia depurálos, hierarquizá-los, ordená-los em nome de um conhecimento verdadeiro, em nome dos direitos de uma ciência detida por alguns" (FOUCAULT, 2004, p. 171). Assim pensada, a genealogia não se configura propriamente como uma luta "contra os conteúdos, os métodos e os conceitos de uma ciência", mas sim como uma postura necessariamente crítica perante os efeitos de poder centralizadores que estão ligados à instituição e ao funcionamento de determinados discursos majoritários no interior de determinada instituição. Frente ao "tu deves" moral, o imoralista desejo genealógico. De certo modo, talvez a prática genealógica não se distancie de determinado valor de leveza, tal como este é defendido por Italo Calvino (1990, p. 27): uma intervenção em nome de uma subtração do peso, a afirmação do movimento frente à pregnância enrijecedora do sentido. Eis aí, portanto, aquilo pelo que lutamos: ao pensar genealogicamente as relações entre o currículo e os valores, desconfiamos, de toda a moral e de todo o saber baseados no absoluto e no universal, voltando-nos, com leveza e imoralmente, para o questionamento e a invenção contínuas. 


\section{Referências}

BARTHES, Roland. O neutro. São Paulo: Martins Fontes, 2003.

BARTHES, Roland. Aula. São Paulo: Editora Cultrix, 2007.

BOULEZ, Pierre. A música hoje. São Paulo: Editora Perspectiva, 2005.

CALVINO, Italo. Seis propostas para o próximo milênio. São Paulo: Companhia das letras, 1990.

CORAZZA, Sandra Mara. O que quer um currículo? pesquisas pós-críticas em educação. Petrópolis: Voze, 2001.

CORAZZA, Sandra Mara. Fantasias de escritura: filosofia, educação, literatura. Porto Alegre: Editora Sulina, 2010.

CORAZZA, Sandra Mara; TADEU, Tomaz. Composições. Belo Horizonte: Autêntica, 2003.

CORAZZA, Sandra Mara; TADEU, Tomaz; ZORDAN, Paola. Linhas de escrita. Belo Horizonte: Autêntica, 2004.

CORTÁZAR, Julio. A volta ao dia em oitenta mundos (tomo I). Rio de Janeiro: Civilização Brasileira, 2008.

COUTO, Carlos Sequeira. Tópica Estética - Filosofia Música Pintura. Lisboa: Imprensa Nacional-Casa da Moeda, 2001.

DELEUZE, Gilles. Conversações. 1972-1990. Rio de Janeiro: Editora 34, 1992.

DELEUZE, Gilles; GUATTARI, Felix. Mil platôs vol. 1. São Paulo: Editora 34, 1995.

DELEUZE, Gilles; GUATTARI, Felix. Mil platôs vol. 5. São Paulo: Editora 34, 1997.

DELEUZE, Gilles; GUATTARI, Felix. O anti-Édipo. São Paulo: Editora 34, 2010.

DELEUZE, Gilles; PARNET; Claire. Diálogos. São Paulo: Escuta, 1998.

FEIL, Gabriel S. "Nomadismo". In: CORAZZA, Sandra Mara; AQUINO, Julio Groppa. Abecedário: educação da diferença. (p. 128-131). Campinas: Papirus, 2009.

FOUCAULT, Michel. Microfísica do poder. Rio de Janeiro: Graal, 2004.

HEUSER, Ester Maria Dreher. Pensar em Deleuze: violência e empirismo no ensino de filosofia. ljuí: Editora Unijuí, 2010.

KLEE, Paul. Teoria del arte moderno. Buenos Aires: Ediciones Caldén, 1979.

KANDINSKY, Wassily. Ponto e linha sobre plano. São Paulo: Martins Fontes, 2005. 
NIETZSCHE, Friedrich. Genealogia da moral: uma polêmica. São Paulo: Companhia das letras, 1998.

NIETZSCHE, Friedrich. A gaia ciência. São Paulo: Companhia das letras, 2001.

RANCIÈRE, Jacques. “Existe uma estética deleuzeana?”. In ALLIEZ, Eric (Org.). Gilles Deleuze: uma vida filosófica. São Paulo: Ed. 34, 2000.

SATIE, Erik. Memórias de um amnesio. Lisboa: Hiena, 1992.

SILVA, Tomaz Tadeu. Identidades terminais: as transformações na política da pedagogia e na pedagogia da política. Petrópolis: Vozes, 1996.

SYLVESTER, David. Entrevistas com Francis Bacon. São Paulo: Cosac Naify, 2007.

ZOURABICHVILI, François. O vocabulário de Deleuze. Rio de Janeiro: Relume Dumará, 2004 .

Universidade do Estado de Santa Catarina - UDESC Programa de Pós-Graduação em Educação - PPGE Revista Linhas Volume 15 - Número 29 - Ano 2014 revistalinhas@gmail.com 